Case Reports

\title{
The Diagnostic and Etiologic Challenge of Myocarditis in Oncologic Patients: Acute Myocarditis During Induction Treatment with All-Trans Retinoic Acid
}

\author{
${ }^{1}$ Núria Coma, ${ }^{1,3,4}$ Sergio Moral, ${ }^{2}$ Rosa Coll, ${ }^{2}$ Carla Moret, ${ }^{1}$ Xavier Albert and ${ }^{1,3,4}$ Ramon Brugada \\ ${ }^{I}$ Department of Cardiology., Hospital Universitari Doctor Josep Trueta, Spain \\ ${ }^{2}$ Department of Oncology, Institut Català d'Oncologia (Girona), Spain \\ ${ }^{3}$ Department of Medical Science, School of Medicine, University of Girona (Spain), Spain \\ ${ }^{4}$ Centro de Investigación Biomédica en Red de Enfermedades Cardiovasculares (CIBERCV) (Spain), Spain
}

\author{
Article history \\ Received: 18-03-2021 \\ Revised: 06-05-2021 \\ Accepted: 12-05-2021 \\ Corresponding Author: \\ Núria Coma \\ Department of Cardiology., \\ Hospital Universitari Doctor \\ Josep Trueta, Spain \\ Email: ncoma.girona.ics@gencat.cat
}

\begin{abstract}
Myocarditis is an inflammatory disease of the myocardium characterized by myocardial infiltration with inflammatory cells and nonischemic myocytic necrosis. Its diagnosis is based on clinical, electrocardiogram, laboratory and echocardiographic parameters and also cardiac magnetic resonance or endomyocardial biopsy when possible. It occurs primarily as a result of infections that include viruses, parasites, bacteria and fungi. Moreover, there are other causes of myocarditis such as autoimmune diseases and an exposure to toxic substances. Beta-blocker, angiotensin-converting enzyme and haemodynamic support is the first line therapy but the treatment must be adapted to the etiological diagnosis. In cancer patients, myocarditis can be caused by infections, autoimmune diseases, but also as an adverse effect of any therapy that modulates the immune system. Uncommon causes in oncologic patients should be considered. Myocarditis induced by all Transretionoic Acid has only been described in a few cases. We present a case of young women with a recent diagnosis of acute promyolicitic leukemia that develops myocarditis during induction therapy with all Transretinoic Acid in the setting of Retinoic Acid Syndrome. The clinical history, physical examination, electrocardiogram, laboratory results, transthoracic echocardiography, cardiac magnetic resonance and coronary angiography were integrated to reach a prompt diagnosis and etiological approach. A neurohormonal inhibitor treatment and corticosteroid therapy were rapidly initiated. Unlike other cases reported, the hematologic treatment was continued with at lower doses without withdrawing. This different approach could provide a new therapeutic management in similar situations.
\end{abstract}

Keywords: Myocarditis, Infections, All-Trans Retinoic Acid, Retinoic Acid Syndrome, Etiology Oncology

\section{Introduction}

Myocarditis is an inflammatory disease of the heart characterized by cell infiltration into the myocardium. Its incidence is about 22 per 100000 individuals (Vos et al., 2015), although probably is underestimated since definitive diagnosis is provided by endomyocardial biopsy which is rarely performed. For its treatment, the diagnosis of myocarditis is required but also the etiological one. Clinical, electrocardiogram, laboratory and echocardiographic parameters lead to a suspicious diagnosis and Cardiac Magnetic Resonance (CMR) usually corroborates it. This myocardial inflammation is predominantly mediated by viral infections, but may also be induced by bacterial, protozoal or fungal infections as well as an exposure to toxic substances or immunemediated diseases. Beta-blocker, angiotensin-converting enzyme and haemodynamic support is the first line therapy. Additionally, the treatment must be adapted to the etiological diagnosis (Bonaca et al., 2019; Kociol et al., 2020; Ammirati et al., 2020; Tschöpe et al., 2020). 
In cancer patients, usually immunocompromised population, myocarditis can be caused by infections but also as an adverse effect of any therapy that modulates the immune system. The association between immune checkpoints and myocarditis has largely been described in the literature and the report incidence is about 0.04 to $1.14 \%$ (Palaskas et al., 2020). However, other oncological therapies such as All Transretinoic Acid (ATRA), have a minor and less frequently described association with myocarditis. ATRA is used followed by anthracycline chemotherapy in acute promyelocitic Leukemia (LAM) and has improved the outcome of this disease. Myocarditis secondary to ATRA is infrequent and has been recently documented in the setting of Retinoic Acid Syndrome (RAS), a complication during LAM treatment with a report incidence about $15 \%$. In this situation, beyond the usual treatment of myocarditis with neurohormonal inhibitors, ATRA treatment is usually withdrawn and can condition the patient's prognosis (Frankel et al., 1992; Stahl and Tallman, 2019; Fabbiano et al., 2005).

We report a case of myocarditis associated to ATRA administration during induction treatment of LAM with an accurate differential diagnosis and with a new approach according to patient's evolution.

\section{Case Presentation}

A 40-year-old woman with obesity, untreated hypertension and gestational diabetes was referred to our hospital for metrorrhagia and skin diathesis, diagnosing her with high-risk acute promyelocytic leukemia. At admission the patient was hemodynamically stable and clinical examination did not reveal any significant findings. Induction therapy with ATRA was immediately initiated with idarubicin on day 1, 3, 5 and 7 and supportive therapy with platelet and plasma transfusions as required. Screening Transthoracic Echocardiography (TTE) performed before induction therapy reported a Left Ventricular Ejection Fraction (LVEF) of $65 \%$ with global longitudinal strain (GLS) of $-23.4 \%$ (Fig. 1A).

At $17^{\text {th }}$ day of ATRA treatment the patient complained of chest pain and was immediately referred to the cardiologist. The physical examination revealed that the patient was tachycardic (138 beats per minute), with a tendency to hypotension but with normal oxygen saturation and no signs of heart failure. No murmurs were detected. The electrocardiogram revealed sinus tachycardia with diffuse ST segment elevation and PR descens (Fig. 1B).

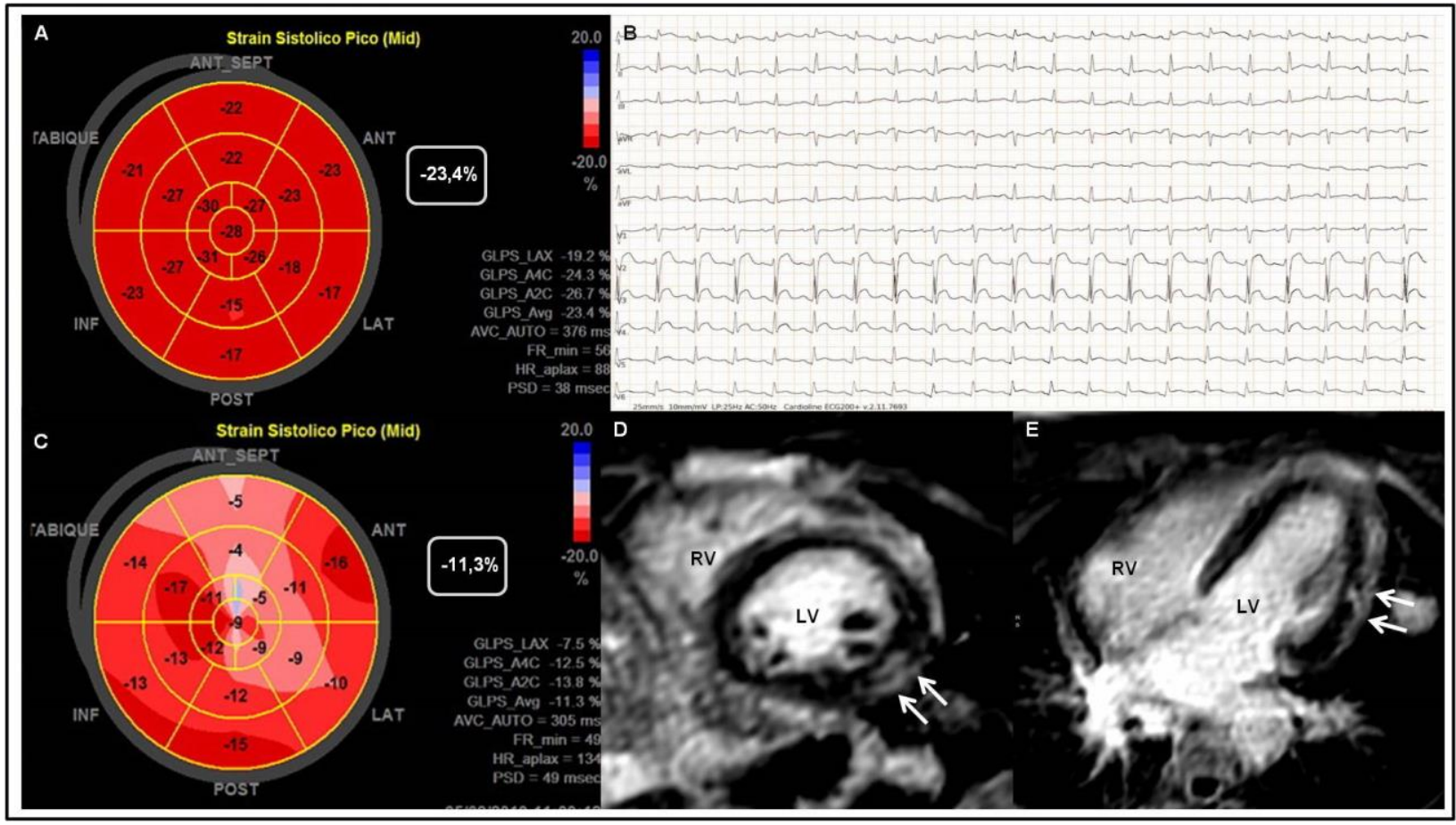

Fig. 1:(A) Screening transthoracic echocardiography demonstrating normal Global Longitudinal Strain before ATRA treatment. (B) Electrocardiogram showing sinus tachycardia with diffuse ST segment elevation and PR descens. (C) After ATRA treatment, transthoracic echocardiography shows a decrease in Global Longitudinal Strain. (D and E) CMR images: Short-axis and four-chamber views respectively in the late enhancement sequences with Gadolinium, depicting typical myocardial signal hyperintensity of the left ventricular lateral wall with subepicardial distribution (arrows). RV = Right Ventricle; LV = Left Ventricle 
High-sensitivity cardiac troponin $\mathrm{T}$ and $\mathrm{N}$-terminal pro-B-type natriuretic peptide levels were elevated up to $1700 \mathrm{ng} / \mathrm{L}$ (normal <14) and $13597 \mathrm{pg} / \mathrm{mL}$ (normal $<300 \mathrm{pg} / \mathrm{mL}$ ), respectively. Urgent TTE revealed antero-lateral and mid-apical severe hypokinesis with LVEF of $50 \%$ and a significant decrease in GLS (-11,3\%), without pericardial effusion (Fig. 1C). Coronary angiography ruled out coronary lesions and CMR confirmed the diagnosis of myocarditis showing mild left ventricular dysfunction with the typical hyperintensity myocardial signal of the left ventricular lateral wall (Fig. 1D and 1E). Due to severe thrombocytopenia, an endomyocardial biopsy was not performed to corroborate the diagnosis. Treatment with captopril and bisoprolol was initiated at low doses and both medications were titrated progressively.

Laboratory results ruled out viral (adenovirus, parvovirurs, hepatitis $\mathrm{B}$ and $\mathrm{C}$, herpes simplex and zoster, Epstein Barr, cytomegalovirus, coxsackie B), thyroid and autoimmune diseases as the etiology of myocarditis. Considering the time of exposure to the oncologic therapy and having excluded other plausible causes, a diagnosis of myocarditis induced by ATRA was made, as an isolated manifestation of RAS. The beta-blocker and angiotensin-converting enzyme was maintained and the patient improved. We reduced the dose of ATRA by half without withdrawing and started corticoid therapy with a close follow-up with clinical, analytical and imaging techniques.

In the following days, the patient recovered uneventfully, the echocardiography and analytics normalized and she was discharged after 23 days of hospitalization. Second-line therapy with ATRA and arsenic trioxide was continued, maintaining cardioprotective treatment, without further complications and the patient achieved a complete morphologic and molecular remission.

\section{Discussion}

Myocarditis is an inflammatory disease of the myocardium that may occur as a consequence of infections, immune system activation or exposure to toxic substances. The treatment of myocarditis is based on an early diagnosis of the pathology but also of the etiology of the disease, which usually also requires specific therapy. Its diagnosis is frequently a challenge since the clinical presentation of myocarditis includes a wide spectrum of symptoms, ranging from mild chest pain to cardiogenic shock. Furthermore, the electrocardiogram is often nonspecific and the echocardiography and cardiac biomarkers may simulate an acute coronary syndrome. Thus, clinical, electrocardiographic and echocardiographic criteria must be integrated to reach a diagnosis. CMR usually corroborates the clinical suspicion, but when there are still doubts, a confirmatory endomyocardial biopsy is recommended (Fig. 2). Prompt diagnosis and specific treatment strategies according to etiology are needed to improve prognosis (Bonaca et al., 2019; Kociol et al., 2020). Viruses are the main cause, but also other infectious agents including bacteria, protozoa and fungi may be the source. Moreover, a wide variety of toxic substances and drugs, such as immune checkpoint inhibitors, as well as systemic autoimmune disorders, can also induce myocarditis (Fig. 3) (Ammirati et al., 2020; Tschöpe et al., 2020).

In our case, the diagnostic suspicion of myocarditis was made based on clinical, electrocardiographic, cardiac biomarkers and echocardiographic criteria. Acute coronary syndrome was ruled out by coronary angiography and CMR corroborated the diagnosis of the disease. The etiological diagnosis was made by the results of laboratory tests and clinical presentation, excluding most frequent viral and other infectious causes as parasitic, bacterial or fungal, as well as the main autoimmune diseases. The timing between clinical presentation and the initiation of oncology therapy supports ATRA treatment as the etiology of myocarditis.

To date, there are only a few cases described of myocarditis induced by ATRA, which are summarized in Table 1 (Stahl and Tallman, 2019; Fabbiano et al., 2005; Klein et al., 2007; Manna et al., 2008; van Rijssel et al., 2010; Isik et al., 2010; Choi et al., 2011; Vassilakopoulos et al., 2017). In this clinical context, myocarditis is generally associated with RAS, a syndrome which was first described by Frankel et al. (1992) and characterized by cytokine-mediated systemic inflammatory response caused by pro-inflammatory cytokines. The reported incidence of RAS induced by ATRA is about $15 \%$ and usually occurs at a median of 12 days after therapy initiation. The most common manifestations are pulmonary infiltrates, fever, body weight gain and kidney failure. Myocarditis was first described as a rare manifestation of RAS in 2005 (Stahl and Tallman, 2019) and has only been reported in a few occasions as case reports (Stahl and Tallman, 2019; Fabbiano et al., 2005; Klein et al., 2007; Manna et al., 2008; van Rijssel et al., 2010; Isik et al., 2010; Choi et al., 2011; Vassilakopoulos et al., 2017). Myocarditis is usually treated with beta-blocker and angiotensinconverting enzyme, especially if there is ventricular dysfunction or heart failure, to reduce inflammation, adverse remodeling, scar formation and the risk of arrhythmia (Tschöpe et al., 2020). On the other hand, the treatment of RAS consists of starting early steroid treatment with intravenous dexamethasone and suspending or decreasing the dose of ATRA depending on the severity of the syndrome (Frankel et al., 1992). 
In our case, although myocarditis was the isolated manifestation of RAS, the timing and favorable course of the illness under corticosteroid therapy suggest this etiology. It should be noted that unlike other myocarditis, when this occurs in the context of RAS, it requires treatment with corticosteroids. Furthermore, in those cases, ATRA treatment is usually withdrawn since the acute cardiological complication is attributed to it. Nevertheless, in our patient, the early diagnosis, specific cardiac treatment and favorable outcome made it possible to maintain ATRA treatment with at lower doses without withdrawing. This different approach could provide a new therapeutic management in similar situations with the prognostic implications of maintaining oncological treatment.

Table 1: Summary of APL cases complicated with ATRA induction treatment

\begin{tabular}{|c|c|c|c|c|c|c|c|c|}
\hline Study & Age & Start day & Symptoms & $\begin{array}{l}\text { RAS } \\
\text { syndrome }\end{array}$ & $\begin{array}{l}\text { Diagnostic } \\
\text { criteria }\end{array}$ & $\begin{array}{l}\text { Pericardial } \\
\text { effusion }\end{array}$ & Treatment & Outcome \\
\hline $\begin{array}{l}\text { Fabbiano et al. } \\
(2005)\end{array}$ & 45 & Induction +24 & $\begin{array}{l}\text { Fever } \\
\text { Muscle pain } \\
\text { No cardiac symptoms }\end{array}$ & No & $\begin{array}{l}\text { Elevated biomarker } \\
\text { ECG } \\
\text { Echocardiogram }\end{array}$ & Minimal & $\begin{array}{l}\text { Withdraw } \\
\text { ATRA } \\
\text { Corticotherapy }\end{array}$ & $\begin{array}{l}\text { Recovered } \\
\text { Recovered }\end{array}$ \\
\hline $\begin{array}{l}\text { Klein et al. } \\
(2007)\end{array}$ & 34 & Induction +19 & $\begin{array}{l}\text { Fever } \\
\text { Chest pain }\end{array}$ & No & $\begin{array}{l}\text { Elevated biomarker } \\
\text { ECG } \\
\text { Echocardiogram }\end{array}$ & Minimal & $\begin{array}{l}\text { Withdraw } \\
\text { ATRA } \\
\text { Corticotherapy }\end{array}$ & Recovered \\
\hline $\begin{array}{l}\text { Klein et al. } \\
(2007)\end{array}$ & 46 & Induction +23 & $\begin{array}{l}\text { Fever } \\
\text { Chest pain }\end{array}$ & No & $\begin{array}{l}\text { Elevated biomarker } \\
\text { ECG } \\
\text { Echocardiogram } \\
\text { CMR }\end{array}$ & No & $\begin{array}{l}\text { Withdraw } \\
\text { ATRA } \\
\text { Corticotherapy }\end{array}$ & \\
\hline $\begin{array}{l}\text { Manna et al. } \\
(2008)\end{array}$ & 23 & Induction +6 & $\begin{array}{l}\text { Fever } \\
\text { Dyspnea } \\
\text { Diffuse muscular } \\
\text { pain Weight increase }\end{array}$ & Yes & $\begin{array}{l}\text { Elevated biomarker } \\
\text { ECG } \\
\text { Echocardiogram }\end{array}$ & No & $\begin{array}{l}\text { Withdraw } \\
\text { ATRA }\end{array}$ & Recovered \\
\hline $\begin{array}{l}\text { Van Rijssel et al. } \\
(2010)\end{array}$ & 58 & Induction +21 & $\begin{array}{l}\text { Fever } \\
\text { Chest pain }\end{array}$ & No & $\begin{array}{l}\text { Elevated biomarker } \\
\text { ECG } \\
\text { Autopsy }\end{array}$ & No reported & --- & $\begin{array}{l}\text { Sudden death } \\
\text { (2 days later) }\end{array}$ \\
\hline Isik et al. (2010) & 9 & Induction +7 & $\begin{array}{l}\text { Palpitations } \\
\text { Heart failure } \\
\text { Thrombophlebitis, } \\
\text { Sweet-syndrome } \\
\text { like lesions }\end{array}$ & No & $\begin{array}{l}\text { Elevated biomarker } \\
\text { ECG } \\
\text { Echocardiogram }\end{array}$ & Yes & $\begin{array}{l}\text { Withdraw } \\
\text { ATRA } \\
\text { Corticotherapy }\end{array}$ & Recovered \\
\hline Choi et al. (2011) & 39 & Induction +18 & $\begin{array}{l}\text { Fever } \\
\text { Dyspnea } \\
\text { Chest pain }\end{array}$ & Yes & $\begin{array}{l}\text { Elevated biomarker } \\
\text { ECG } \\
\text { Echocardiogram } \\
\text { CT coronary }\end{array}$ & No & $\begin{array}{l}\text { Withdraw } \\
\text { ATRA } \\
\text { Corticotherapy }\end{array}$ & Recovered \\
\hline $\begin{array}{l}\text { Vassilakopoulos } \\
\text { et al. }(2017)\end{array}$ & 17 & Induction +22 & Chest pain & No & $\begin{array}{l}\text { Elevated biomarker } \\
\text { ECG } \\
\text { Echocardiogram }\end{array}$ & No & $\begin{array}{l}\text { Withdraw } \\
\text { ATRA } \\
\text { Corticotherapy }\end{array}$ & Recovered \\
\hline $\begin{array}{l}\text { El Makki et al. } \\
\text { (2019) }\end{array}$ & 27 & Induction +10 & $\begin{array}{l}\text { Chestpain } \\
\text { Orthopnea }\end{array}$ & No & $\begin{array}{l}\text { Elevated biomarker } \\
\text { ECG } \\
\text { Echocardiogram }\end{array}$ & Minimal & $\begin{array}{l}\text { Withdraw } \\
\text { ATRA }\end{array}$ & Recovered \\
\hline
\end{tabular}

\section{DIAGNOSIS OF MYOCARDITIS}

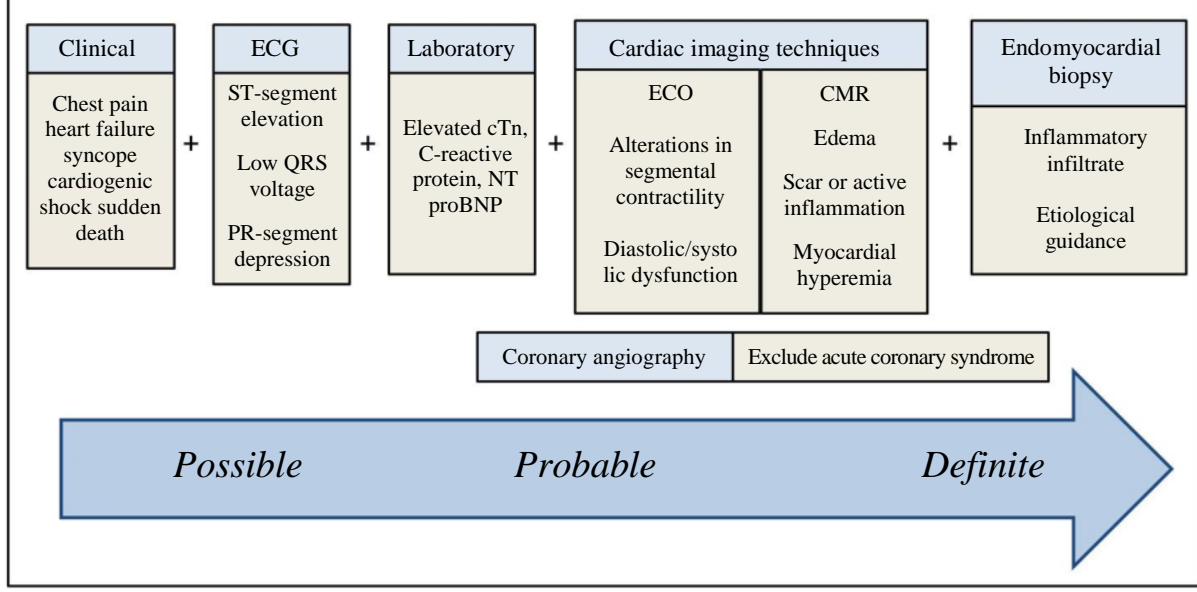

Fig. 2: A proposed approach to myocarditis diagnosis. cTn = cardiac Troponin; NTproBNP $=$ N-Terminal pro-B-type Natriuretic Peptide; ECO = Echocardiography; CMR = Cardiac Magnetic Resonance 


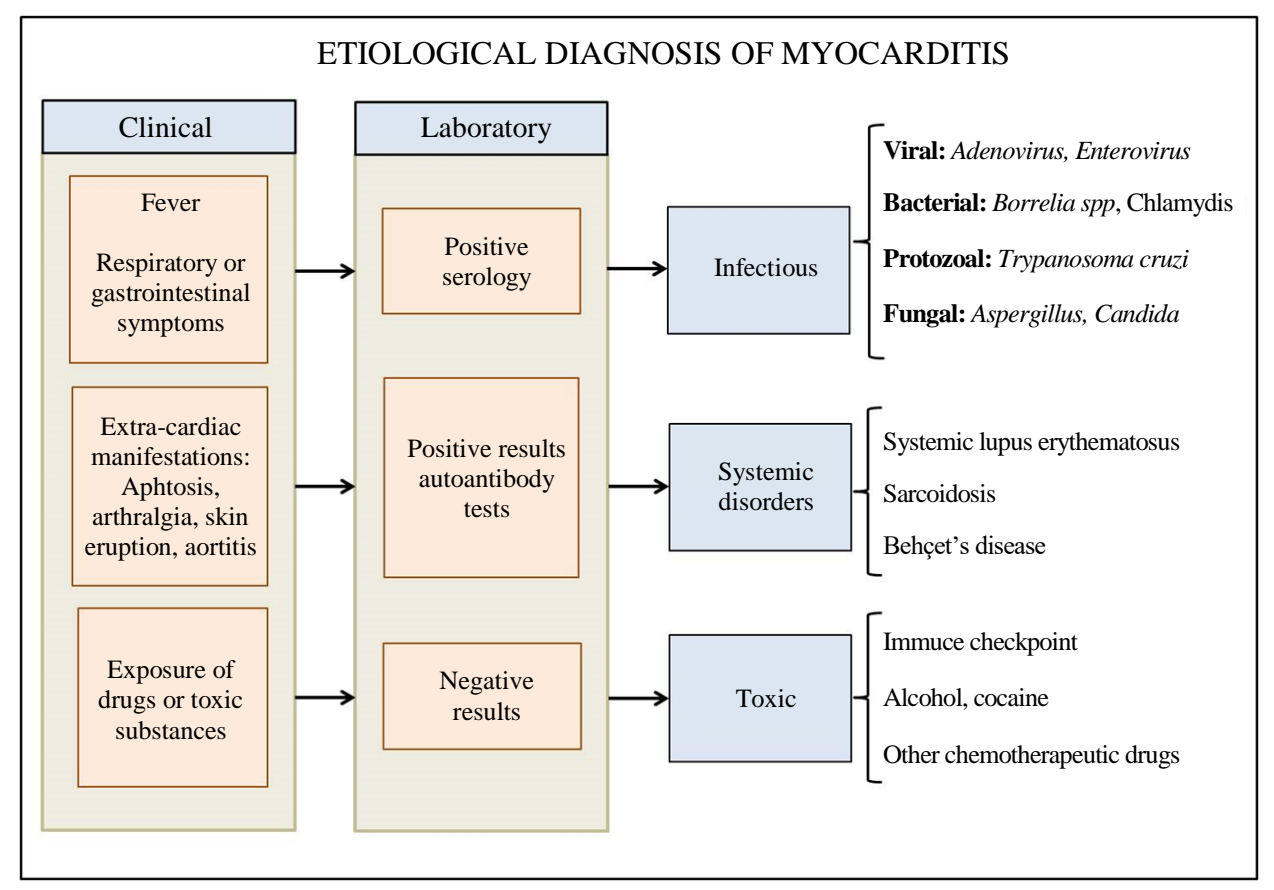

Fig. 3: A propose approach to define the etiology of myocarditis (etiological diagnosis)

\section{Acknowledgment}

Our special thanks to the Cardiac Imaging Unit for the involvement in this case and help to reach a prompt diagnosis.

\section{Author's Contributions}

All authors equally contributed in this work.

\section{Ethics}

This article is original and contains unpublished material. The corresponding author confirms that all of the other authors have read and approved the manuscript and no ethical issues involved.

\section{References}

Ammirati, E., Frigerio, M., Adler, E. D., Basso, C., Birnie, D. H., ... \& Camici, P. G. (2020). Management of Acute Myocarditis and Chronic Inflammatory Cardiomyopathy: An Expert Consensus Document. Circulation: Heart Failure, 13(11), e007405.

https://doi.org/10.1161/CIRCHEARTFAILURE.120 .007405

Bonaca, M. P., Olenchock, B. A., Salem, J. E., Wiviott, S. D., Ederhy, S., ... \& Moslehi, J. (2019). Myocarditis in the setting of cancer therapeutics: proposed case definitions for emerging clinical syndromes in cardiooncology. Circulation, 140(1), 80-91. https://doi.org/10.1161/CIRCULATIONAHA.118.0 34497
Choi, S., Kim, H. S., Jung, C. S., Jung, S. W., Lee, Y. J., Rheu, J. K., ... \& Lee, N. H. (2011). Reversible symptomatic myocarditis induced by all-trans retinoic acid administration during induction treatment of acute promyelocytic leukemia: rare cardiac manifestation as a retinoic acid syndrome. Journal of Cardiovascular Ultrasound, 19(2), 95-98. https://doi.org/10.4250/jcu.2011.19.2.95

El Makki, A. B., El Mehdi Mahtat, J. K., Bouzelmat, H., \& Chaib, A. (2019). A rare case of perimyocarditis induced by all-trans retinoic acid administration during induction treatment of acute promyelocytic leukemia. Medicine and Pharmacy Reports, 92(4), 418. https://doi.org/10.15386/mpr-1229

Fabbiano, F., Magrin, S., Cangialosi, C., Felice, R., Mirto, S., \& Pitrolo, F. (2005). All-trans retinoic acid induced cardiac and skeletal myositis in induction therapy of acute promyelocytic leukaemia. British Journal of Haematology, 129(3), 444-445. https://doi.org/10.1111/j.1365-2141.2005.05465.x

Frankel, S. R., Eardley, A., Lauwers, G., Weiss, M., \& Warrell Jr, R. P. (1992). The" retinoic acid syndrome" in acute promyelocytic leukemia. Annals of Internal Medicine, 117(4), 292-296. https://doi.org/10.7326/0003-4819-117-4-292

Isik, P., Çetin, I., Tavil, B., Azik, F., Kara, A., Yarali, N., \& Tunc, B. (2010). All-transretinoic acid (ATRA) treatment-related pancarditis and severe pulmonary edema in a child with acute promyelocytic leukemia. Journal of Pediatric Hematology/Oncology, 32(8), e346-e348. https://doi.org/10.1097/MPH.0b013e3181e75731 
Klein, S. K., Biemond, B. J., \& van Oers, M. H. (2007). Two cases of isolated symptomatic myocarditis induced by all-trans retinoic acid (ATRA). Annals of Hematology, 86(12), 917-918. https://doi.org/10.1007/s00277-007-0333-3

Kociol, R. D., Cooper, L. T., Fang, J. C., Moslehi, J. J., Pang, P. S., Sabe, M. A., ... \& American Heart Association Heart Failure and Transplantation Committee of the Council on Clinical Cardiology. (2020). Recognition and initial management of fulminant myocarditis: a scientific statement from the American Heart Association. Circulation, 141(6), e69-e92. https://doi.org/10.1161/CIR.0000000000000745

Manna, A., Cadenotti, L., Motto, A., \& Ballo, P. (2008). Reversible cardiac dysfunction without myocytolysis related to all-trans retinoic acid administration during induction therapy of acute promyelocytic leukemia. Annals of Hematology, 88(1), 91-92. https://doi.org/10.1007/s00277-008-0552-2

Palaskas, N., Lopez-Mattei, J., Durand, J. B., Iliescu, C., \& Deswal, A. (2020). Immune checkpoint inhibitor myocarditis: pathophysiological characteristics, diagnosis and treatment. Journal of the American Heart Association, 9(2), e013757. https://doi.org/10.1161/JAHA.119.013757

Stahl, M., \& Tallman, M. S. (2019). Differentiation syndrome in acute promyelocytic leukaemia. British Journal of Haematology, 187(2), 157-162. https://doi.org/10.1111/bjh.16151
Tschöpe, C., Ammirati, E., Bozkurt, B., Caforio, A. L., Cooper, L. T., Felix, S. B., ... \& Van Linthout, S. (2020). Myocarditis and inflammatory cardiomyopathy: current evidence and future directions. Nature Reviews Cardiology, 12, 1-25. https://www.nature.com/articles/s41569-020-00435-x

van Rijssel, R. H., Wegman, J., Oud, M. E., Pals, S. T., \& van Oers, M. H. (2010). A case of ATRA-induced isolated myocarditis in the absence of circulating malignant cells: demonstration of the $\mathrm{t}(15 ; 17)$ translocation in the inflammatory infiltrate by in situ hybridisation. Leukemia research, 34(7), e142-E144. https://doi.org/10.1016/j.leukres.2009.12.005

Vassilakopoulos, T. P., Asimakopoulos, J. V., Plata, E., Kelepesis, G., Petevi, K., Koutsi, C., ... \& Meletis, J. (2017). Recurrent acute myopericarditis without effusion during ATRA induction and ATO salvage of APL: a variant form of the differentiation syndrome? Leukemia \& lymphoma, 58(7), 1743-1746. https://doi.org/10.1080/10428194.2016.1253838

Vos, T., Barber, R. M., Bell, B., Bertozzi-Villa, A., Biryukov, S., Bolliger, I., ... \& Brugha, T. S. (2015). Global, regional and national incidence, prevalence and years lived with disability for 301 acute and chronic diseases and injuries in 188 countries, 19902013: a systematic analysis for the Global Burden of Disease Study 2013. The Lancet, 386(9995), 743-800. https://doi.org/10.1016/S0140-6736(15)60692-4 